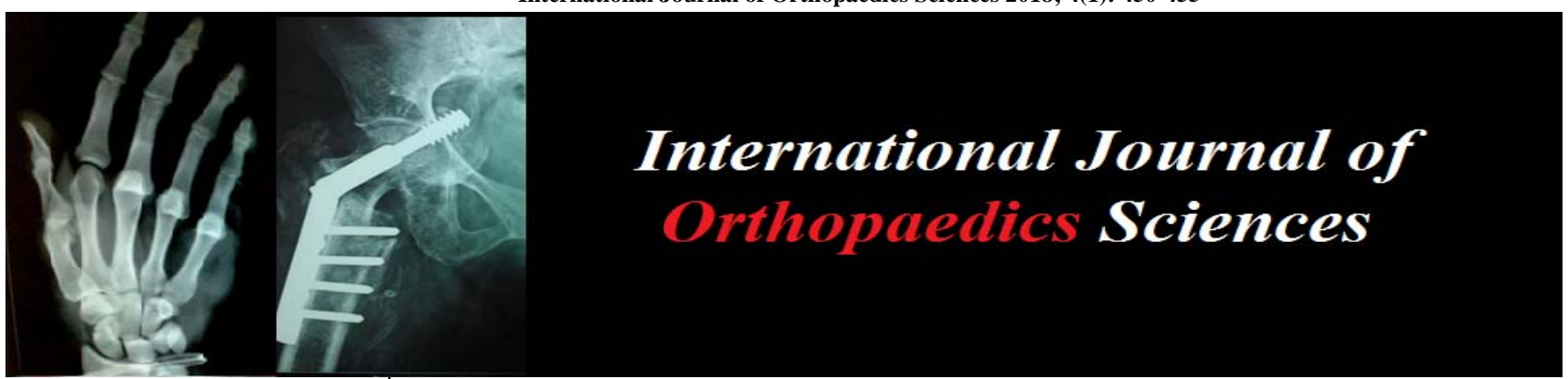

ISSN: 2395-1958

IJOS 2018; 4(1): 450-455

(C) 2018 IJOS

www.orthopaper.com

Received: 11-11-2017

Accepted: 12-12-2017

Sharath Ramanatha Kittanakere Associate Professor, Department of Orthopaedics Ramaiah Medical College Bangalore, Karnataka, India

Rahul Prakash Bhonsle Junior Resident, Department of Orthopaedics Ramaiah Medical College Bangalore, Karnataka, India

\section{Ramneesh Kohli}

Junior Resident, Department of Orthopaedics Ramaiah Medical College Bangalore, Karnataka, India

Dr. Kiran Daggubatti Junior Resident, Department of Orthopaedics Ramaiah Medical College Bangalore, Karnataka, India

\section{Correspondence}

Rahul Prakash Bhonsle Junior Resident, Department of Orthopaedics Ramaiah Medical College Bangalore, Karnataka, India

\section{Prospective study of posterior condylar offset ratio and its influence on maximal flexion angle of knee in posterior cruciate ligament substituting total knee arthroplasty}

\author{
Sharath Ramanatha Kittanakere, Rahul Prakash Bhonsle, Ramneesh \\ Kohli and Dr. Kiran Daggubatti
}

DOI: https://doi.org/10.22271/ortho.2018.v4.i1g.65

\section{Abstract}

Background: Osteoarthritis of the knee is a common clinical problem that affects elderly and few young individuals. It is associated with symptoms like pain, stiffness and limitation of activity. Total Knee Arthroplasty is an effective surgical modality that reduces pain, improves patients' quality of life, and increases functional capability in patients with severe osteoarthritis of knee. Role of Posterior Condylar Offset on Range of movements has always been a controversial topic. The present study has been taken up by us because studies conducted by western authors reported conflicting outcomes.

Materials and Methods: This was a prospective study in which Patients with diagnosis of osteoarthritis knee presenting in Department of Orthopaedics at a tertiary care hospital and willing to undergo surgery were included depending upon inclusion and exclusion criteria. Assessment of knee was done preoperatively and postoperatively to obtain functional outcome of TKA clinically by using knee society score and oxford knee score and radiologically to obtain PCO and PCOR.

Results: We found no significant correlation between post-operative Posterior Condylar Offset (mean 25.94+/-1.89), Posterior Condylar Offset Ratio (mean 0.45+/-0.02) with Maximum Flexion Angle (mean $115.93+/-9.59$ ) with $\mathrm{p}$ value 0.136 and 0.995 respectively.

Conclusion: Maximum flexion angle after Total Knee Arthroplasty is a multivariate hence Posterior Condylar Offset and Posterior Condylar Offset Ratio cannot be used as an independent variable for the quantification of functional outcome of Total Knee Arthroplasty. Moreover, accurate radiographic measurement of pre-operative Posterior Condylar Offset is not possible as the cartilage thickness remained was not accounted for and also there is an inherent error in the measurement techniques that accounts for inconsistent findings.

Keywords: Total Knee Arthroplasty, Posterior condylar offset, Posterior Condylar Offset Ratio, Maximum Flexion Angle, Outcome

\section{Introduction}

Osteoarthritis of the knee is a common clinical problem that affects elderly and few young individuals associated with symptoms like pain, stiffness and limitation of activity and an associated clinical sign like swelling, effusion, crepitus, impingement, instability and malalignment ${ }^{[1]}$. OA is more prevalent in developed than in developing regions of the world. In the United States survey, indicated that $85 \%$ of the population 75 years of age and older were affected. Nearly $60 \%$ of Americans with arthritis were women. Osteoarthritis of the knee represents an important subset of the overall OA burden and is the leading cause of functional disability ${ }^{[2]}$. Age and female gender are invariant risk factors associated with increased incidence of knee OA. According to a number of published reports, anywhere from $6 \%$ to over $13 \%$ of men, but between $7 \%$ and $19 \%$ of women, over 45 years of age are affected, resulting in a $45 \%$ less risk of incidence in men. The other risk factors include obesity, genetic predisposition, autoimmune conditions, trauma to menisci or cruciate ligaments etc. The radiographic hallmarks of primary osteoarthritis are the: asymmetrical joint space narrowing or loss, subchondral sclerosis (increased bone formation around the joint), subchondral cyst 
formation, and osteophytes. Imaging techniques like 3D CT and MRI may help in imaging of the joint and surrounding soft tissue structures as well as ligament and menisci ${ }^{3}$. The management principally consist of reduction of pain, stiffness, and to improve the physical functioning, retarding the disease's progression of joint damage and improvement of quality of life. The gold standard treatment of choice is Total Knee Arthroplasty ${ }^{[4]}$.

TKA is an effective surgical modality that reduces pain, improves patient's quality of life, and increases functional capability. Total knee arthroplasty (TKA) gives good subjective and objective results during the first 15 years after implantation. The principal goal of TKA is to reduce joint pain during standing, walking and during routine daily activities. Maintenance of range of motion (ROM) is essential for all these purposes. The range of flexion of the knee obtained after TKA is often limited and may be determined by several factors, including pre-operative range of movements 1 , posterior femoral condylar offset ${ }^{[5]}$, posterior tibial slope ${ }^{[6]}$, surgical technique, joint line elevation, postoperative physiotherapy and the design of the implant ${ }^{[7-11]}$. The effects of these factors in surgeries where either posterior cruciate ligament is retained or prosthesis is used as a substitute of PCL and this has been studied extensively in various randomized controlled trials. But the influence of femoral condylar offset and posterior tibial slope in surgeries where PCL is sacrificed is concerned there are very few studies addressing this issue.

As far as the previous studies are concerned the role of PCO on ROM is still a controversy. Studies conducted by Goldstein et al ${ }^{[12]}$, Massin and Gournay ${ }^{[13]}$ had significant correlation whereas; study by Ishii Y et al ${ }^{[14]}$, Kim JH ${ }^{[15]}$ stated that PCO has no significant correlation with knee flexion. Moreover there are not many studies on the influence of PCO and PCOR on cruciate substituting knee, hence the purpose of this study was to sort out the controversy in PCL substituting TKA.

\section{Materials and Methods}

This was a prospective study of Patients with diagnosis of osteoarthritis knee presenting in Department of Orthopaedics of a tertiary care hospital situated in an urban areas and who have undergone surgery during the study period. Assessment of knee was done preoperatively and postoperatively to obtain functional outcome of TKA clinically by using knee society score and oxford knee score and radiologically to obtain PCO and PCOR. Patients were mainly assessed for Knee pain, total range of movement, varus and valgus alignments and stability (anterio-posteriorly and medio-laterally). Patients were further assessed for functions like walking, climbing stairs, walking aids used (or) not. Posterior Condylar Offset (PCO) and Ratio (PCOR) were calculated using the the software called "OsiriX"e which is an image processing application used in our hospital for viewing radiographs and calculating the radiographic variables. PCO and PCOR were measured in all the true lateral view radiographs as described by Bellamans et al and Soda $\mathrm{Y}$ et al ${ }^{[17]}$ respectively. True lateral view knee joint was considered to be with both the femoral condyles overlapping. Relevant imaging and biochemical tests were done in all the patients. Doppler, ECG and 2D ECHO was done in selected patients as part of preanasthetic evaluation. Surgery was done by senior orthopaedic surgeon.

\section{Surgical Procedure}

Under Spinal anaesthesia with Epidural analgesia, patient in supine position scrubbed, painted and draped in sterile manner using disposable drapes after application of tourniquet. Medial parapatellar approach was taken using 14 $\mathrm{cm}$ incision with knee in flexion. Skin flaps created with superficial dissection and incision taken over the quadriceps tendon and extended distally around the medial border of patella and along the medial border of patellar tendon. Distal femoral cuts were made at a valgus angle of 5 to 7 degrees with the anatomical axis of femur. The amount of femoral cuts was determined by the thickness of the distal femoral prosthesis. Tibial resection was performed to produce 7 degree to 10 degree of postoperative PTS irrespective of the previous value. The anteroposterior cuts were performed for insertion of prosthesis by approximating the anteroposterior diameter of the femur measured intraoperatively. The rotational alignment of the femoral component was obtained with reference to the Whiteside's line, transepicondylar axis, and posterior condylar axis. the trial implants were used to check for medio lateral, antero posterior stability throughout the range of movements and patellar tracking, thus confirming the sizing of the implants. Tibial tray was implanted first using polymethylmethacrylate (PMMA) cement applied over the cut surfaces at its doughy state after making sure that the blood and fat doesn't get mixed with the cement. Similarly the femoral component was implanted with the cement. Excess cement was then removed from the periphery of the component. After the femoral component has been seated, carefully extend the knee with a trial tibial spacer in place to ensure complete seating of the femoral prosthesis. Knee was kept in extension till the cement was set. Wound was closed in layers with drain after the repair of quadriceps and retinaculum. Skin approximated using staples and cleaned with betadine solution.
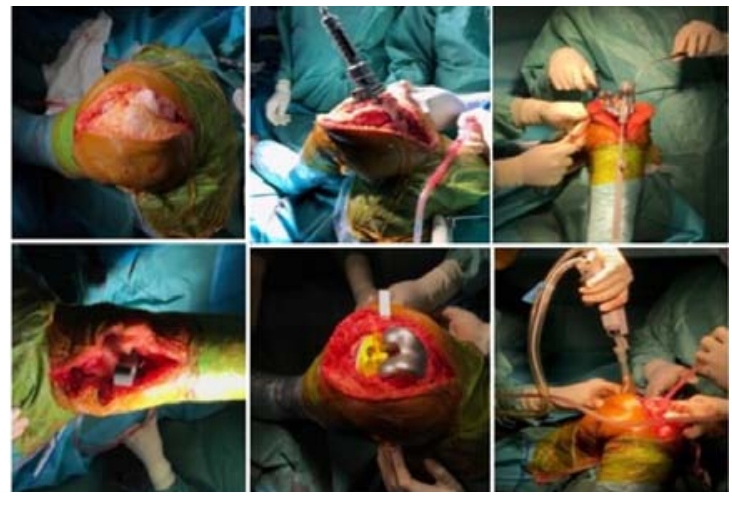

Fig 1: Steps of surgical procedure (Clockwise from left upper corner): Medial Parapatellar approach, distal femoral cuts with jig, proximal tibial cuts with jig, Bone cuts with spacer, trial implant and pulse lavage irrigation.

Post operatively Patients were started with full weight bearing walking with the walker and knee ROM with or without the assistance of a continuous passive motion machine as tolerated from the first postoperative day. Postoperative rehabilitation protocol included ROM exercises, lower extremity muscle strengthening, concentrating on the quadriceps; gait training, and instruction in performing basic activities of daily living. Patients were told to avoid squatting or sitting cross legged or using Indian toilets. A predefined questionnaire was given to the patients at pre-operative time, at 1 month post-operative time and similarly at 3 and 6 months post op. The answers were put to get the computer generated scores. The results were divided into grades like excellent, 
good, fair and poor. Based upon various other studies minimum sample size required was found to be 31 so we included 35 patients in our study. The statistical analysis was done using SPSS 18.0 version.

\section{Inclusion criteria}

1. Patients with primary osteoarthritis diagnosed clinically and radiologically.

2. In skeletally matured patients with age group of $35-85$ years.

\section{Exclusion criteria}

1. Patients with $>20$ degree of fixed flexion deformity

2. Post traumatic arthritis

3. Revision TKA

4. Any morphological defects in femur or tibia.

\section{Results}

In our prospective study involved 32 patients with severe knee osteoarthritis underwent total knee arthroplasty using Zimmer Next Gen LPS system with 11 patients underwent bilateral TKA and 21 patients underwent unilateral TKA. 22 patients were females (16 patients unilateral and 6 patients bilateral) and 10 patients were males (5 patients unilateral and 5 patients bilateral).

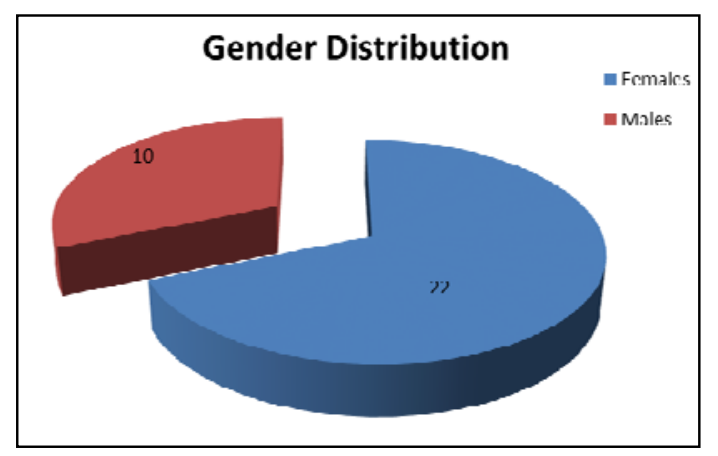

Fig 2: Gender Distribution of the studied cases.

The mean pre-operative maximum flexion angle was $96.63 \pm 9.11$ degree which showed significant correlation with the post-operative maximum flexion angle with mean of $115.93 \pm 9.59(\mathrm{p}=<0.001)$.

Table 1: Maximum flexion angle significance

\begin{tabular}{|c|c|c|}
\hline Pair & r value & P value \\
\hline Pre Op MFA vs Post Op MFA & 0.700 & $<0.001^{* *}$ \\
\hline Pre Op MFA vs 3 Months MFA & 0.525 & $<0.001^{* *}$ \\
\hline Pre Op MFA vs 6 Months MFA & 0.582 & $<0.001^{* *}$ \\
\hline
\end{tabular}

The mean pre-operative PCO was $26.42 \pm 1.88$ and mean postoperative PCO was $25.94 \pm 1.89$ and statistically there was no significant correlation between them $(\mathrm{p}=0.097)$.

Table 2: Posterior condylar offset significance

\begin{tabular}{|c|c|c|c|c|c|}
\hline variables & Pre & Post & Difference & t value & P value \\
\hline PCO & $26.42 \pm 1.88$ & $25.94 \pm 1.89$ & 0.479 & 1.698 & $0.097+$ \\
\hline
\end{tabular}

The mean pre-operative PCOR was $0.45 \pm 0.02$ and the mean postoperative PCOR was $0.45 \pm 0.02$ and statistically there was no significant correlation between them.

Table 3: Posterior condylar offset ratio significance

\begin{tabular}{|c|c|c|c|c|c|}
\hline variables & Pre & Post & Difference & $\begin{array}{c}\mathbf{t} \\
\text { value }\end{array}$ & $\begin{array}{c}\text { P } \\
\text { value }\end{array}$ \\
\hline PCOR & $0.45 \pm 0.02$ & $0.45 \pm 0.02$ & 0.005 & 1.368 & 0.179 \\
\hline
\end{tabular}

The mean pre-operative knee society score was $36.30 \pm 13.34$ and the mean post-operative knee society score $79.23 \pm 5.37$ which showed significant improvement after TKA. The mean pre-operative oxford knee society score was $12.44 \pm 2.91$ and the mean post-operative oxford knee score was $36.86 \pm 3.03$ which showed significant improvement after TKA.

Total 43 knees in 32 patients were operated upon. The age distribution of the cases showed that the most common age group to be affected was $61-70$ years $(51.2 \%)$ followed by 50 60 years $(30.2 \%)$ and $71-80$ years $(18.6 \%)$.

Table 4: Age distribution

\begin{tabular}{|c|c|c|}
\hline Age in years & No. of Knees $(\mathbf{n}=\mathbf{4 3})$ & $\mathbf{\%}$ \\
\hline $50-60$ & 13 & 30.2 \\
\hline $61-70$ & 22 & 51.2 \\
\hline $71-80$ & 8 & 18.6 \\
\hline
\end{tabular}

19 patients underwent right knee TKA and 24 patients with left knee TKA.

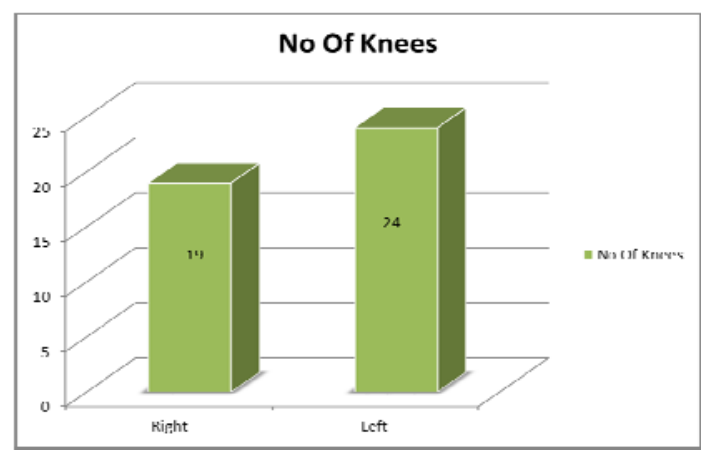

Fig 3: Side distribution

Out of 43 knees, 27 knees were of Grade 4 Kellgren and Lawrence and 16 knees were of Grade 3 Kellgren and Lawrence.

Table 5: Classification of osteoarthritis

\begin{tabular}{|c|c|c|}
\hline & No. of Knees & $\%$ \\
\hline Grade 1 & 0 & 0 \\
\hline Grade 2 & 0 & 0 \\
\hline Grade 3 & 16 & 37.2 \\
\hline Grade 4 & 27 & 62.8 \\
\hline Total & 43 & 100 \\
\hline
\end{tabular}

Preoperative Maximum Flexion angle, Knee society score and Oxford knee score was noted in all patients.

Table 6: Preoperative Maximum Flexion angle, Knee society score and Oxford knee score

\begin{tabular}{|c|c|c|c|}
\hline \multirow{4}{*}{$\begin{array}{c}\text { Preoperative } \\
\text { Maximum Flexion } \\
\text { angle }\end{array}$} & & No. of Knees & $\%$ \\
\cline { 2 - 4 } & $80-90 \mathrm{deg}$ & 18 & 41.9 \\
\cline { 2 - 4 } & $91-105 \mathrm{deg}$ & 17 & 39.5 \\
\cline { 2 - 4 } & $106-115 \mathrm{deg}$ & 8 & 18.6 \\
\hline \multirow{4}{*}{$\begin{array}{c}\text { Preoperative } \\
\text { Knee society score }\end{array}$} & $80-100$ & 43 & 100 \\
\cline { 2 - 4 } & (excellent) & 0 & 0 \\
\cline { 2 - 4 } & $70-79$ (good) & 0 & 0 \\
\cline { 2 - 4 } & $60-69$ (fair) & 4 & 9.3 \\
\cline { 2 - 4 } & $<60$ (poor) & 39 & 90.7 \\
\hline \multirow{4}{*}{$\begin{array}{c}\text { Preoperative } \\
\text { Oxford knee score }\end{array}$} & Total & 43 & 100 \\
\cline { 2 - 4 } & $0-19$ & 30 & 93.0 \\
\cline { 2 - 4 } & $20-29$ & 0 & 7.0 \\
\cline { 2 - 4 } & $30-39$ & 43 & 0 \\
\cline { 2 - 4 } & $40-48$ & 0 & 100 \\
\hline
\end{tabular}

Postoperative Maximum Flexion angle, Knee society score and Oxford knee score was also determined in all patients. 
Table 7: Postoperative Maximum Flexion angle, Knee society score and Oxford knee score

\begin{tabular}{|c|c|c|c|}
\hline \multirow{4}{*}{$\begin{array}{c}\text { Postoperative } \\
\text { Maximum Flexion } \\
\text { angle }\end{array}$} & $\begin{array}{c}\text { No. of } \\
\text { Knees }\end{array}$ & \% \\
\cline { 2 - 4 } & $130-120 \mathrm{deg}$ & 22 & 51.2 \\
\cline { 2 - 4 } & $119-110 \mathrm{deg}$ & 15 & 34.9 \\
\cline { 2 - 4 } & $109-100 \mathrm{deg}$ & 5 & 11.6 \\
\cline { 2 - 4 } & $99-90 \mathrm{deg}$ & 1 & 2.3 \\
\hline \multirow{4}{*}{$\begin{array}{c}\text { Postoperative } \\
\text { Knee society score }\end{array}$} & $80-100$ & 43 & 100 \\
\cline { 2 - 4 }$($ excellent) & 17 & 39.5 \\
\cline { 2 - 4 } & $70-79$ (good) & 23 & 53.5 \\
\cline { 2 - 4 } & $60-69$ (fair) & 3 & 7 \\
\cline { 2 - 4 } & $<60$ (poor) & 0 & 0 \\
\hline \multirow{4}{*}{$\begin{array}{c}\text { Postoperative } \\
\text { Oxford knee score }\end{array}$} & $0-19$ & 43 & 100 \\
\cline { 2 - 4 } & $20-29$ & 1 & 2.3 \\
\cline { 2 - 4 } & $30-39$ & 33 & 76.7 \\
\cline { 2 - 4 } & $40-48$ & 43 & 100 \\
\cline { 2 - 4 } & Total & 43 & 21 \\
\hline
\end{tabular}

There was no correlation between post-operative PCO (mean $25.94 \pm 1.89$ ) and 6 months maximum flexion angle (mean $115.93 \pm 9.59$ ) with $\mathrm{p}=0.136$.

Table 8: Comparison between post op PCO and MFA

\begin{tabular}{|c|c|}
\hline post-operative PCO and MFA & P value \\
\hline Post Op PCO vs Immediate post op & 0.006 \\
\hline Post Op PCO vs MFA 3 months & 0.006 \\
\hline Post Op PCO vs MFA 6 months & 0.136 \\
\hline
\end{tabular}

There was no correlation between post-operative PCOR

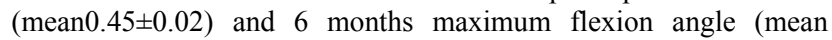
$115.93 \pm 9.59)$ with $\mathrm{p}=0.995$

Table 9: Comparison between post op PCOR and MFA

\begin{tabular}{|c|c|}
\hline post-operative PCOR and MFA & P value \\
\hline Post Op PCOR vs Immediate post op & 0.901 \\
\hline Post Op PCOR vs MFA 3 months & 0.781 \\
\hline Post Op PCOR vs MFA 6 months & 0.995 \\
\hline
\end{tabular}

While doing the analysis of Comparison between PCO difference and MFA, Pearson correlation showing no significance.
Table 10: Comparison between PCO difference and MFA

\begin{tabular}{|c|c|c|}
\hline $\begin{array}{c}\text { Comparison between PCO difference and } \\
\text { MFA }\end{array}$ & $\begin{array}{c}\text { r } \\
\text { value }\end{array}$ & $\begin{array}{c}\text { P } \\
\text { value }\end{array}$ \\
\hline $\begin{array}{c}\text { PCO difference vs MFA Immediate } \\
\text { Post Op }\end{array}$ & -0.047 & 0.764 \\
\hline PCO difference vs MFA 3 months & -0.158 & 0.312 \\
\hline PCO difference vs MFA 6 months & -0.030 & 0.846 \\
\hline
\end{tabular}

While doing the analysis of Comparison between PCOR difference and MFA, Pearson correlation showing no significance.

Table 11: Comparison between PCOR difference and MFA

\begin{tabular}{|c|c|c|}
\hline $\begin{array}{c}\text { Comparison between PCOR difference and } \\
\text { MFA }\end{array}$ & $\begin{array}{c}\text { r } \\
\text { value }\end{array}$ & $\begin{array}{c}\text { P } \\
\text { value }\end{array}$ \\
\hline $\begin{array}{c}\text { PCOR difference vs MFA Immediate } \\
\text { Post Op }\end{array}$ & -0.130 & 0.406 \\
\hline PCOR difference vs MFA 3 months & -0.073 & 0.642 \\
\hline PCOR difference vs MFA 6 months & 0.007 & 0.964 \\
\hline
\end{tabular}

The analysis of complication seen in studied cases showed that the most common complication was wound problems (18.6\%) followed by stiffness (7\%) and infection (4.6\%).

Table 12: Complication seen in patients with TKA

\begin{tabular}{|c|c|c|}
\hline Complications & No. of Knees & \% \\
\hline Wound problems & 8 & $18.6 \%$ \\
\hline Infection & 2 & $4.6 \%$ \\
\hline Thromboembolism & 0 & 0 \\
\hline Patellofemoral disorders & 1 & $2.3 \%$ \\
\hline Peroneal nerve palsy & 0 & 0 \\
\hline Periprosthetic fractures & 0 & 0 \\
\hline Polyethylene wear & 1 & $2.3 \%$ \\
\hline Aseptic Loosening & 0 & 0 \\
\hline Instability & 1 & $2.3 \%$ \\
\hline Stiffness & 3 & $7 \%$ \\
\hline
\end{tabular}

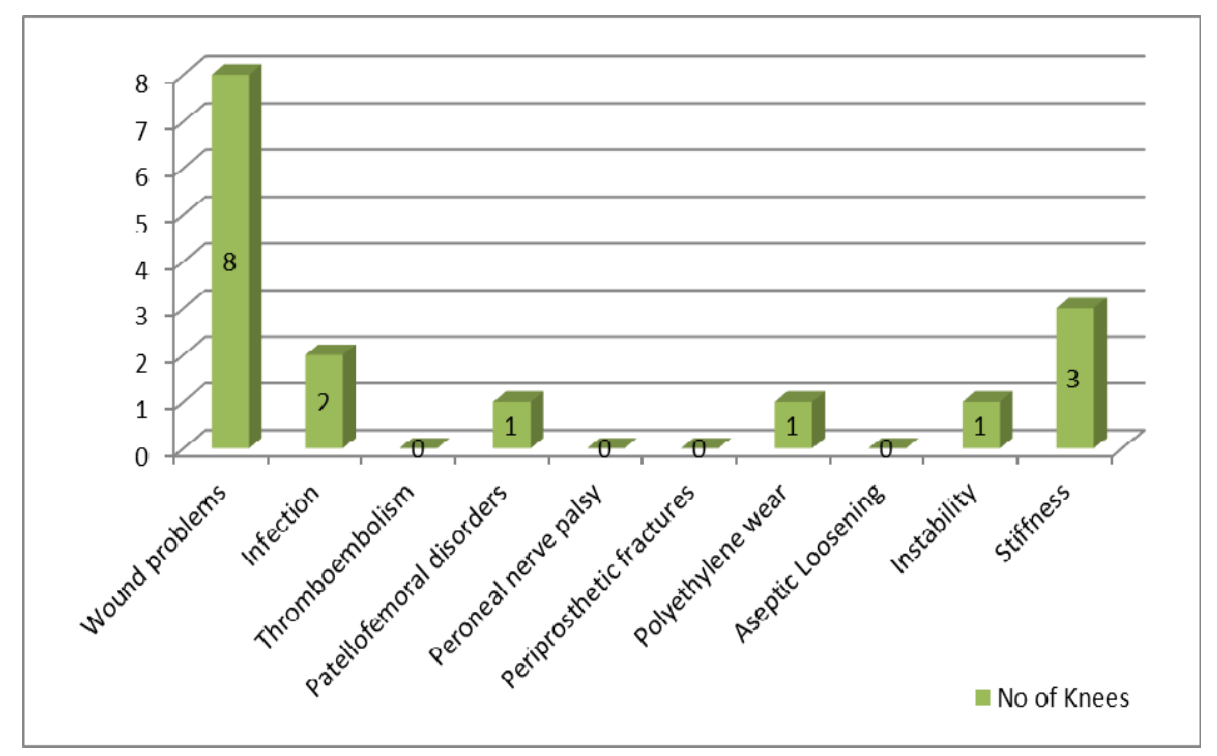

Fig 4: Complication seen in patients with TKA.

\section{Discussion}

Range of movements after total knee replacement is a very important factor to determine the functional outcome of the procedure especially in a country like India where activities of daily living requires more amount of flexion. Knee arthroplasty is a complex surgery with its functional outcome 
depending upon the operative skills with good clinical exposure and the familiarities with the instrumentation and designs of the implants ${ }^{[16]}$.

Maximum flexion angle of less the 70 degrees are associated with poor walking abilities and minimum of flexion angle 110 degree is required for daily activities. Hence it has been an area of research in case of total knee arthroplasty. According to the previous studies, flexion angle is multivariate factor depending on the age, sex, obesity, pre-operative range of movements, mediolateral stability, deformities, pre-operative mental illness, rehabilitation, surgical techniques involving flexion extension gap balancing, posterior cruciate ligament balancing, femoral component placement, joint line elevation, posterior condylar clearance, posterior condylar offset, tibial slope, and the prosthetic designs and also the postoperative arthrofibrosis ${ }^{17}$. However, the factors like the posterior condylar offset and tibial slope are the topics of controversy and not much studies are done to conclude the same. Bellamans et al, stated that 1 degree of extra gain in posterior tibial slope resulted in an average 1.7 degree increase in maximum flexion angle in PCL retaining knees. Similar results were reported by Malviya et al ${ }^{[18]}$, 1degree of PTS increase lead to the increase in maximal flexion angle by an average of 2.3 degree in 101 knees after PCL-retaining TKA. Negative results were reported in PCL sacrificing TKA by Kansara and Markel [19], Piazza et al ${ }^{[20]}$ and Verra W C ${ }^{[21]}$.

In our study, posterior tibial slope was kept constant to 7-10 degree for all the knees to minimize the bias. Design of the implant was also kept constant to minimize the bias as different designs will have different kinematics which would affect the knee ROM. Knee flexion in theory is limited by direct impingement of the posterior aspect of the tibial component against the posterior femur shaft with paradoxical anterior translation of femoral component during flexion. This was shown by Bellamans et al in his fluoroscopic study with $72 \%$ patients exhibiting the same with the concept of posterior condylar offset. According to him, every $1 \mathrm{~mm}$ decrease in PCO resulted in 6.1 degree reduction in maximum flexion angle in PCL retaining knee. Similar results were reported in the studies done by Goldstein et al, Massin and Gournay and Frank R on PCL retaining TKA ${ }^{[22]}$.

We also followed the methods used by Bellamans et al to calculate the PCO and we found no change in maximum flexion angle. In some patients PCO was found to be increased and some were found with PCO decreased but almost all of our patients had good maximum flexion angle.

Kim et al also reported no influence of PCO and PCOR on flexion angle PCL sacrificing TKA with study involving two groups one with 1.2-mm reduction in the $\mathrm{PCO}$ and the other with any reduction. Similar results were found in studies done by Rajshekar $\mathrm{K}^{[23]}$ Hanratty et al ${ }^{[24]}$ and Bauer et al ${ }^{[25]}$ on PCL sacrificing TKA whereas Arabori et al ${ }^{[26]}$ on PCL substituting TKA. The significance of PCO appears to be less in the posterior stabilized or posterior-sacrificing knee prosthesis as per the previous studies. This could be due to the kinematics and rollback being controlled by the prosthesis design that reduces the risk of impingement, rather than being constrained by the native posterior cruciate ligament.

Theoretically the value of PCO differs with the body type of the patient especially the size of the knee joint. Hence the study on posterior clearance cannot be done with just by PCO for which a ratio had to considered as described by Soda et al [27] i.e., PCOR which according to him had correlation with the maximum flexion angle on cruciate substituting knee. But our results came to be contrary as per the study by Soda et al and our study results were similar to the study done by Kim et al. Moreover, maximum flexion angle after TKA is a multivariate hence PCO and PCOR cannot be used as an independent variable for the quantification of functional outcome of TKA ${ }^{[28]}$. This has been shown in our study where the pre-operative maximum flexion angle was correlated significantly with the post-operative maximum flexion angle.

Clark HD [29] has stated in his study that the accurate radiographic measurement of pre-operative $\mathrm{PCO}$ is not possible as the cartilage thickness remained was not accounted for and also there is an inherent error in the measurement techniques that accounts for inconsistent findings. This can be attributed for the controversy of the PCO and PCOR on maximum flexion angle ${ }^{[30]}$.

Functional outcome in our study was assessed with knee society scores and oxford knee scores which showed significant improvement after TKA when compared to preoperative scores.

Eight cases of our patients had wound problems like the superficial infections and stitch abscess which were managed with minor debridement and prolonged antibiotic care, whereas, two cases had infection which needed re exploration, debridement, and thorough wash with 3 weeks of IV antibiotic care. Three cases of arthrofibrosis were managed with continuous passive motion and vigorous physiotherapy. Patient with instability was put on long knee brace for 4 weeks.

\section{Conclusion}

Maximum flexion angle after Total Knee Arthroplasty is a multivariate hence Posterior Condylar Offset and Posterior Condylar Offset Ratio cannot be used as an independent variable for the quantification of functional outcome of Total Knee Arthroplasty. Moreover, accurate radiographic measurement of pre-operative Posterior Condylar Offset is not possible as the cartilage thickness remained was not accounted for and also there is an inherent error in the measurement techniques that accounts for inconsistent findings.

\section{Conflict Of Interest: None}

\section{References}

1. Heidari B. Knee osteoarthritis prevalence, risk factors, pathogenesis and features: Part I. Caspian Journal of Internal Medicine. 2011; 2(2):205-212.

2. McAlindon TE, Cooper C, Kirwan JR, Dieppe PA. Determinants of disability in osteoarthritis of the knee. Annals of the Rheumatic Diseases. 1993; 52(4):258-262.

3. Oo WM, Linklater JM, Hunter DJ. Imaging in knee osteoarthritis. Curr Opin Rheumatol. 2017; 29(1):86-95.

4. Katz JN. Appropriateness of Total Knee Replacement. Arthritis \& rheumatology (Hoboken, NJ). 2014; 66(8):1979-1981.

5. Bellemans J, Banks S, Victor J, Vandenneucker H, Moemans A. Fluoroscopic analysis of the kinematics of deep flexion in total knee arthroplasty. Bone \& Joint Journal. 2002; 84(1):50-3.

6. Bellemans J, Robijns F, Duerinckx J, Banks S, Vandenneucker $H$. The influence of tibial slope on maximal flexion after total knee arthroplasty. Knee Surgery, Sports Traumatology, Arthroscopy. 2005; 13(3):193-6.

7. Anouchi YS, McShane M, Kelly Jr F, Elting J, Stiehl J. Range of motion in total knee replacement. Clinical 
orthopaedics and related research. 1996; 331:87-92

8. Kawamura H, Bourne RB. Factors affecting range of flexion after total knee arthroplasty. Journal of orthopaedic science. 2001; 6(3):248-52.

9. Kurosaka M, Yoshiya S, Mizuno K, Yamamoto T. Maximizing flexion after total knee arthroplasty: the need and the pitfalls. The Journal of arthroplasty. 2002; 17(4):59-62.

10. Chiu KY, Ng TP, Tang WM, Yau WP. Knee flexion after total knee arthroplasty. Journal of orthopaedic surgery. 2002; 10(2):194-202.

11. Dennis DA, Komistek RD, Scuderi GR, Zingde S. Factors affecting flexion after total knee arthroplasty. Clinical orthopaedics and related research. 20071; 464:53-60.

12. Goldstein WM, Raab DJ, Gleason TF, Branson JJ, Berland $\mathrm{K}$. Why posterior cruciate retaining and substituting total knee replacements have similar ranges of motion: the importance of posterior condylar offset and cleanout of posterior condylar space. JBJS. 2006; 88(suppl_4):182-8.

13. Massin $\overline{\mathrm{P}}$, Gournay A. Optimization of the posterior condylar offset, tibial slope, and condylar roll-back in total knee arthroplasty. The Journal of arthroplasty. 2006; 21(6):889-96.

14. Ishii $\mathrm{Y}$, Noguchi $\mathrm{H}$, Takeda M, Sato J, Toyabe SI. Posterior condylar offset does not correlate with knee flexion after TKA. Clinical Orthopaedics and Related Research ${ }^{\circledR} .2013 ;$ 471(9):2995-3001.

15. Kim JH. Effect of posterior femoral condylar offset and posterior tibial slope on maximal flexion angle of the knee in posterior cruciate ligament sacrificing total knee arthroplasty. Knee surgery \& related research. 2013; 25(2):54.

16. SANNA M, SANNA C, CAPUTO F, PIU G, SALVI M. Surgical approaches in total knee arthroplasty. Joints. 2013; 1(2):34-44.

17. Judge A, Arden NK, Cooper C, Kassim Javaid M, Carr AJ, Field RE et al. Predictors of outcomes of total knee replacement surgery. Rheumatology (Oxford). Epub, 2012; 51(10):1804-13.

18. Malviya A, Lingard EA, Weir DJ, Deehan DJ. Predicting range of movement after knee replacement: the importance of posterior condylar offset and tibial slope. Knee Surgery, Sports Traumatology, Arthroscopy. 2009; 17(5):491-8.

19. Kansara D, Markel DC. The effect of posterior tibial slope on range of motion after total knee arthroplasty. The Journal of arthroplasty. 2006; 21(6):809-13.

20. Piazza SJ, Delp SL, Stulberg SD, Stern SH. Posterior tilting of the tibial component decreases femoral rollback in posterior-substituting knee replacement: A computer simulation study. Journal of orthopaedic research. 1998; 16(2):264-70.

21. Verra WC, van den Boom LGH, Jacobs WCH, Schoones JW, Wymenga AB, Nelissen RGHH. Similar outcome after retention or sacrifice of the posterior cruciate ligament in total knee arthroplasty: A systematic review and meta-analysis. Acta Orthopaedica. 2015; 86(2):195201.

22. Kolisek FR, McGrath MS, Marker DR. PosteriorStabilized Versus Posterior Cruciate Ligament-Retaining Total Knee Arthroplasty. The Iowa Orthopaedic Journal. 2009; 29:23-27.

23. Thippanna RK, Mahesh P, Kumar MN. PCL-retaining versus PCL-substituting TKR - Outcome assessment based on the "forgotten joint score." Journal of Clinical Orthopaedics and Trauma. 2015; 6(4):236-239.

24. Hanratty BM, Thompson NW, Wilson RK, Beverland DE. The influence of posterior condylar offset on knee flexion after total knee replacement using a cruciatesacrificing mobile-bearing implant. Bone \& Joint Journal. 2007; 89(7):915-8.

25. Bauer T, Biau D, Colmar M, Poux X, Hardy P, LortatJacob A. Influence of posterior condylar offset on knee flexion after cruciate-sacrificing mobile-bearing total knee replacement: a prospective analysis of 410 consecutive cases. The Knee. 2010; 17(6):375-80.

26. Arabori M, Matsui N, Kuroda R, Mizuno K, Doita M, Kurosaka $\mathrm{M}$ et al. Posterior condylar offset and flexion in posterior cruciate-retaining and posterior stabilized TKA. Journal of Orthopaedic Science. 2008; 13(1):46-50.

27. Soda Y, Oishi J, Nakasa T, Nishikawa K, Ochi M. New parameter of flexion after posterior stabilized total knee arthroplasty: posterior condylar offset ratio on X-ray photographs. Archives of orthopaedic and trauma surgery. 2007; 127(3):167-70.

28. Kane RL, Saleh KJ, Wilt TJ, Bershadsky B. The functional outcomes of total knee arthroplasty. J Bone Joint Surg Am. 2005; 87(8):1719-24.

29. Clarke HD. Changes in posterior condylar offset after total knee arthroplasty cannot be determined by radiographic measurements alone. The Journal of arthroplasty. 2012; 27(6):1155-8.

30. Lee OS, Lee YS. Effect of the Referencing System on the Posterior Condylar Offset and Anterior Flange-Bone Contact in Posterior Cruciate-Substituting Total Knee Arthroplasty. J Arthroplasty. 2017; pii: S08835403(17):31028-8. 